\title{
Gloria y memoria: el retrato funerario en la región de Murcia
}

\author{
Juan Ramón Moreno Vera ${ }^{1}$
}

Resumen: En la colección de arte de la Región de Murcia se conservan tan solo dos ejemplos de retrato funerario, sin embargo se trata de dos obras de carácter excepcional, la primera un sepulcro de mármol renacentista dedicado a la gloria y representación del Obispo Esteban de Almeyda, mientras que el segundo es una representación funeraria infantil nada habitual en las colecciones de pintura institucionales.

Palabras Clave: Retrato, funerario, infantil, sepulcro, mármol, Murcia.

Abstract: In the art collection of the Region of Murcia only two examples of funerary portraiture are preserved although they are extraordinary, the first a marble tomb from renaissance dedicated to the glory and representation of the Bishop Esteban de Almeyda, the second one is child funerary representation very unusual in official paintings collections.

Keywords: Portraiture, funerary, children, tomb, marble, Murcia.

\section{Introducción}

Si hablamos de la más antigua de las tipologías que conforman el género del retrato probablemente tengamos que recurrir al retrato funerario como punto de partida original de este tipo de representaciones humanas destinadas a representar físicamente a seres humanos. En la Antigüedad Clásica se acostumbraba a realizar unas mascarillas funerarias tomadas de la propia cara del difunto para así mantener el recuerdo de los antepasados durante la eternidad. Esta costumbre que los romanos heredaron de los etruscos, ya había sido habitual en otras culturas occidentales como la egipcia aunque se trataba de aproximaciones más o menos idealizadas del protagonista, y no estaban al alcance de la población como en Roma si no que se realizaban para sarcófagos de altas personalidades.

El arte funerario tuvo un fuerte apogeo durante los primeros años del arte paleocristiano cuando la gente deseaba enterrarse cerca de las reliquias de los mártires de la Iglesia que habían dado su sangre por Cristo. Así nacieron los enterramientos $A d$ Sanctas o Ad Martyres, aunque fueron pronto prohibidos por su abuso. El arte funerario quedó prácticamente olvidado durante la Alta Edad Media, aunque comenzó a ser recuperado en época gótica gracias a las tumbas reales que se construían en las nuevas catedrales. Esta leve recuperación gozó de un gran auge en época del Renacimiento, momento en el que el arte sepulcral tuvo un éxito enorme y los grandes gobernantes, reales, civiles o religiosos proyectaron enormes monumentos funerarios a medio camino entre la escultura y la arquitectura para gloria y recuerdo de su personalidad.

En las etapas posteriores el retrato funerario continuó existiendo en los grandes programas sepulcrales, aunque poco a poco fueron introduciéndose también otras técnicas como la pintura, en estas representaciones gloriosas de la muerte, que el cristianismo toleraba por su relación directa con las representaciones triunfantes de Cristo muerto en la cruz.

\footnotetext{
1. Doctor con Mención Europea por la Universidad de Alicante y Licenciado en Historia del Arte, se formó en las Universidades de Murcia, Nápoles y Oxford. Tras trabajar como conservador en la Dirección General de Patrimonio de la Región de Murcia, en el Museo de Bellas Artes de Murcia y en la Galería MOT International de Londres, actualmente desarrolla su labor docente e investigadora en la Universidad de Alicante.jr.moreno@ua.es
} 
Aunque el arte funerario siempre ha tenido predilección por la escultura, durante el siglo XVII y hasta el XIX fue habitual encontrar representaciones postmortem individuales en homenaje y recuerdo a los fallecidos.

Esta clase de retratos funerarios tuvieron en el retrato funerario infantil una de sus ramas más llamativas. En el siglo XIX el retrato funerario pictórico comenzó a ser poco a poco sustituido por un retrato fotográfico de los difuntos, al ser la fotografía un modo más rápido y barato de inmortalizar el recuerdo de los antepasados.

A principios de siglo XX esta clase de representaciones aún seguían vigentes en los países europeos, aunque poco a poco se ha ido perdiendo y difuminando esta costumbre en buena parte de los territorios, siendo más habitual la inclusión de fotografías todavía en vida en las tumbas de los familiares o si se realiza un retrato pictórico en homenaje que también represente al protagonista en vida.

La bibliografía escrita ya sobre el arte funerario en España es extensa, aunque cabe citar la obra pionera de 1919 escrita por Ricardo de Orueta $^{2}$ que fue quien comenzó a dar una importancia real a esta tipología de arte que hasta entonces había sido, casi en exclusiva, materia de estudio para los arqueólogos.

En la Región de Murcia existen también algunos ejemplos de arte funerario dignos de entrar en un análisis completo a nivel nacional, siendo alguno de esos ejemplos las dos obras que se conservan con carácter funerario en el Fondo de Arte de la Región de Murcia (FARM), por una parte el sepulcro del Obispo Esteban de Almeyda, y por otro el retrato infantil funerario que pintó Rafael Tegeo y que se conserva en el Museo de Bellas Artes.

\section{El arte sepulcral en la colección de la Región de Murcia}

Como ya hemos comentado en época renacentista se produce una revitalización del arte funerario gracias al éxito que vive en esta época el sepulcro como monumento funerario para gloria y recuerdo de un individuo tras la muerte. Como indica González de Zárate (1989) la concepción del arte funerario del Renacimiento difiere bastante de otras épocas como la Edad Media o el Barroco. El concepto de lo macabro y la aparición de calaveras y esqueletos, se reemplaza por una plástica más dulce en la que la muerte es concebida como un momento de dormición y los yacentes muestran un rostro que transmite tranquilidad y equilibrio, en la espera de la resurrección de la carne.

Las tumbas renacentistas pretenden exaltar al individuo difunto por lo que suelen disponer complejos programas iconográficos que mezclan lo sacro y lo profano para así poner de manifiesto la grandeza del representado. Normalmente estas representaciones tratan del dignificar el recuerdo además mediante el uso de materiales nobles y la colocación del monumento en un lugar destacado de la iglesia o claustro correspondiente, por lo que el material más usado solía ser el mármol, y el lugar preferido solían ser lo más cerca del presbiterio posible.

El otro de los puntos fuertes que justificaban la realización de un sepulcro, era poner de manifiesto el triunfo de la fama del protagonista sobre la muerte, ya que la fama era considerada en el Renacimiento como el único elemento que sobrevivía eternamente a la muerte. Esta idea entronca directamente con las corrientes petrarquistas de la época muy presentes en el siglo XVI en España gracias a la difusión de su obra Los triunfos.

\footnotetext{
${ }^{2}$ Ricardo de Orueta publicó en 1919 la obra titulada La escultura funeraria en España, aunque en realidad era parte de un proyecto mayor que comenzó en la citada obra con las provincias de Cuenca, Guadalajara y Ciudad Real, analizando el arte sepulcral que en ellas encontró entre los siglos XIII y XVII.
} 
Un resumen interesante de estas ideas lo hace Panofsky:

Estos programas iconográficos en el arte sepulcral se disponen como un canto al hombre, como un instrumento de su exaltación. La iconografía de estos sepulcros en el Renacimiento no se dispone solamente para reconocer la piedad o santidad del finado, también como reconocimiento a su labor política, científica o social. (Panofsky, 1964)

\subsection{Sepulcro del Obispo Esteban de Almeyda}

Dentro de estos términos, y cumpliendo todas las características antes citadas, podemos analizar la primera de las obras de carácter funerario que encontramos en este repaso por el retrato del FARM. Se trata del Sepulcro del Obispo Esteban de Almeyda., realizado en el año 1572 por el escultor italiano Bartolomé de Lugano en mármol de Carrara y que mide 272 por 157 por $133 \mathrm{~cm}$.

Don Esteban de Almeyda, el protagonista, era portugués de nacimiento y fue hijo de Don Diego Fernández de Almeyda, Prior de Ocrato, quien, gracias a sus grandes méritos, ostentó un alto cargo en el Reino de Portugal. El matrimonio entre la Infanta Doña Isabel de Portugal y el emperador Carlos V, fue el motivo por el que Don Esteban de Almeyda pasó al Reino de Castilla ocupando el cargo de capellán de la emperatriz. Las grandes simpatías que despertó en la corte castellana hicieron que en 1532 fuese nombrado Obispo de Astorga y en 1542 fuese nombrado Obispo de León sustituyendo a Don Sebastián Ramírez.

El 13 de Julio de 1546, fue promovido como Obispo de Cartagena siendo sustituido en León por Don Juan Fernández de Temiño. Ya en Murcia, el Obispo Esteban Almeyda, mantuvo muy buena relación con los jesuitas por lo que propició la llegada de la orden a la ciudad.

Según Alcázar (1710), el Obispo Almeyda escribió en 1555 una carta a San Francisco de Borja que se encontraba en Plasencia, por la que pedía encarecidamente que enviase algunos padres jesuitas a Murcia para poder dar inicio a la fundación de un nuevo Colegio en la ciudad. San Francisco, condescendiente, envió cinco padres desde los colegios de Valencia y Gandía, también al primer rector del mismo que, llegado desde Zaragoza, sería Don Juan Bautista de Barna. El Palacio Episcopal recibió a los nuevos padres jesuitas en la ciudad, aunque al poco tiempo ya ocuparon el nuevo Colegio, que empezó su construcción en 1555 en un solar que el Obispo poseía extramuros de la ciudad con un jardín y una casa de recreo, cerca de 'La puerta de los Porceles' y enfrente de la Iglesia de San Miguel. En 1576, empezaron las clases en el Colegio pese a no estar acabada toda la construcción.

El Colegio se iba a destinar en principio a la oración y la evangelización aunque pronto los jesuitas convencieron al Obispo para que también se impartieran clases de Artes, Gramática y Teología convirtiéndose así en uno de los centros de estudios más importantes del país, incluso por delante de algunas universidades. Don Esteban de Almeyda, que había asistido al Concilio de Trento, pensó en el Colegio de San Esteban como un nuevo foco cultural y artístico en la ciudad desde donde poder enseñar a generaciones enteras de murcianos bajo las nuevas premisas impuestas por Trento. Su pasión por cultivar la mente y el espíritu se tradujo también, como comenta Botías (2009), en la donación de su biblioteca particular al Colegio, que fue incrementada también por sus sucesores y que se salvó milagrosamente tras la expulsión de los jesuitas y que fue devuelta a la Iglesia en el Siglo XVIII.

El 19 de Agosto de 1557 el Obispo Almeyda, quien había costeado todas las obras del nuevo colegio, realiza la primera escritura de donación en la que se especifica el uso del Colegio ante el escribano Juan de Jumilla, según cuenta López 
García (2006). En la dotación se incluyen como carga, dos cátedras de gramática, una de retórica, una de moral y una de misión, siendo ocupadas por doce personas que residían en el Colegio. También se especificó en esta donación quienes quedarían como patronos del Colegio: El Obispo de la Diócesis de Cartagena que hubiera en el momento, el Deán y Cabildo de la Santa Iglesia Catedral de Murcia, el Concejo de Murcia, el Corregidor y el Regimiento de la ciudad de Murcia.

Hasta tal punto se identificó el Obispo con el proyecto de San Esteban, que su escudo de armas aparece representado en infinidad de rincones del edificio. Dentro del proyecto del Colegio de San Esteban, claro está, que el Obispo Almeyda prestó mayor atención a la construcción de la Iglesia del centro. Fue en ella donde decidió cristalizar su relación con el colegio al enterrar su cuerpo para que "con esto tengan más memoria de su ánimo" según escribió el primer rector de la fundación. La intención de Esteban de Almeyda fue enterrarse bajo las gradas del presbiterio, y aunque murió el 23 de Marzo de 1563, su cuerpo no fue enterrado en el oratorio del centro hasta que fue acabada su tumba.

El Sepulcro del Obispo Almeyda (Fig. 1) llegó a Murcia en 1572, y fue esculpido por el italiano Bartolomé de Lugano, según se puede leer en el documento de entrega que el propio artista escribió y en el que se puede leer lo siguiente "ahora que yo el dicho Bartolomé de Lugano he traído el dicho túmulo y lo estoy labrando e asentando e poniendo en posición" y donde él mismo reconoce ser milanés, vecino de Alicante y marmolista ${ }^{3}$.

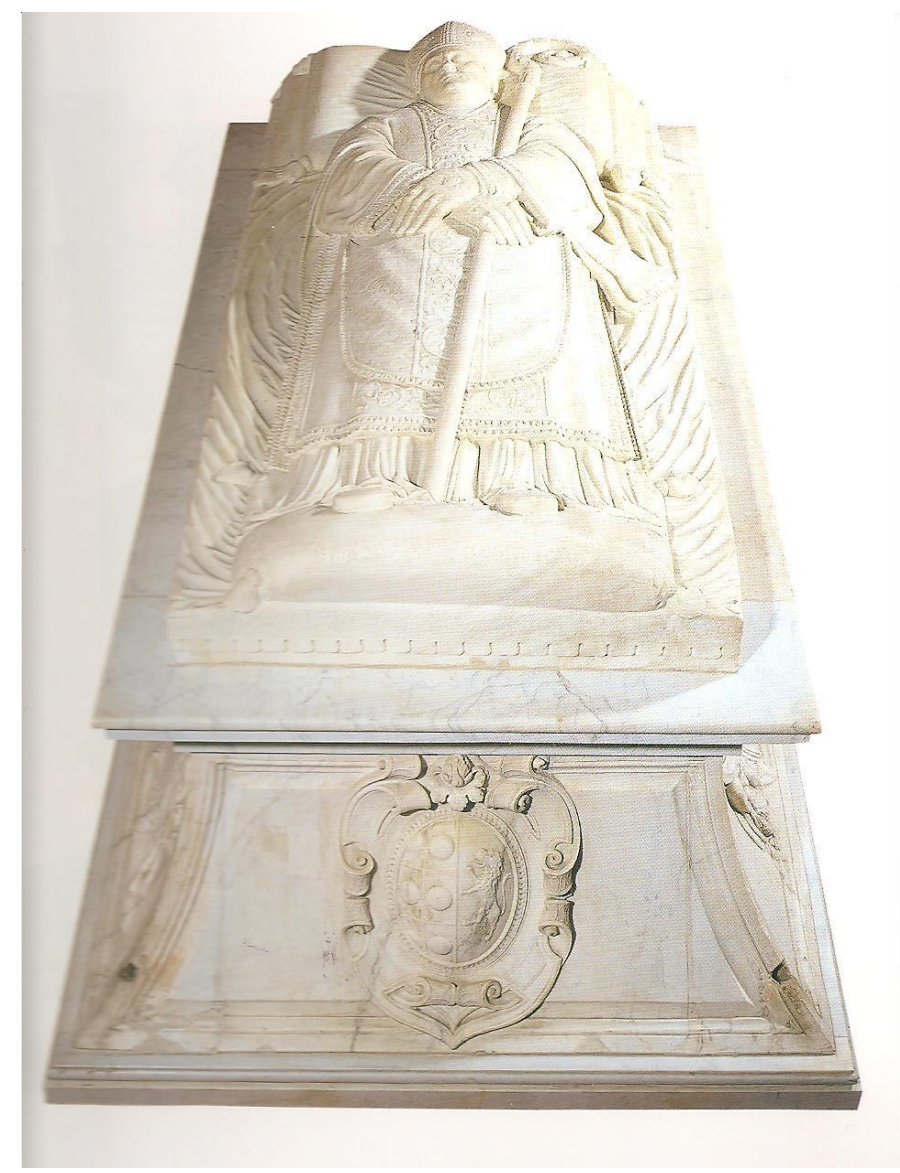

Figura 1. Bartolomé de Lugano. Sepulcro del obispo D. Esteban de Almeyda. 1572. CARM

\footnotetext{
${ }^{3}$ Parte del documento de entrega del sepulcro del obispo Esteban de Almeyda se puede leer en el artículo que Crisanto López-Jiménez escribió el 22 de Noviembre de 1970 en el Diario Línea.
} 
López-Jiménez (1970) afirma que este autor era hermano de Juan de Lugano, también milanés y con taller en la ciudad de Alicante, hecho que no ha podido ser contrastado aunque estudios posteriores de ambos autores sí hablan de un más que posible parentesco familiar entre ambos, como indica López Torrijos (1987). Juan de Lugano fue el artista que realizó supuestamente el Sepulcro de los Condestables en la Catedral de Burgos o el enterramiento del Cardenal Tavera en Toledo, aunque posteriores análisis han demostrado que su participación fue mínima (Cadiñanos, 1983) y su principal actuación, según López Torrijos (1987) fue la de ser el enlace comercial que traía a España obras en mármol del norte de Italia. Según el Marqués de Loyoza (1957) Juan de Lugano fue uno de los últimos representantes del clan de los Gazini y de los Aprile, oriundos del Lago de Lugano y establecidos en Génova, sin embargo, según Gutiérrez-Cortines (1972) las figuras de Juan y de Bartolomé, nos aparecen bastante desdibujadas ya que carecemos de datos suficientes sobre su actividad profesional. Es más, en el documento el artista asegura que ha "traído" el sepulcro lo cual puede ser interpretado como que lo hubiera labrado casi en su totalidad en otro sitio, ya fuera desde el taller de Alicante o desde Génova.

Como analiza Redondo Cantera (1986) la influencia que tuvo el sepulcro que Sixto IV se construyó en su capilla de la Basílica de San Pedro del Vaticano fue fundamental en el arte sepulcral renacentista español. Según Redondo en el modelo de Sixto IV el éxito del modelo creado por Pollaiuolo se basó en tres aspectos fundamentalmente: el primero fue la propia condición exenta del monumento funerario, que se alejaba de los modelos murales que se habían extendido en las tumbas papales durante toda la Edad Media y el Renacimiento; el segundo aspecto, que causó gran impacto fue la originalidad de una decoración figurada rodeando el sepulcro; y el tercer punto fue la propia construcción del túmulo donde la cama se apoya sobre un tronco de pirámide con paredes cóncavas.

El primer ejemplo de modelo de cama sobre tronco piramidal cóncavo en un monumento funerario español fue la tumba del Príncipe Don Juan en el convento de Santo Tomás de Ávila, creado en 1513 por Domenico Fancelli, escultor florentino relacionado con el círculo de Donatello y también con los círculos de Carrara.

Siguiendo esta línea podemos encontrar en el sureste el Sepulcro de Juan de $\mathrm{Orea}^{4}$, hecho por Diego Fernández de Villalán en la Catedral de Almería, y el Sepulcro del Obispo Esteban de Almeyda, en la Iglesia de San Esteban de Murcia, debido a manos italianas, como fueron las de Bartolomé de Lugano quien nos dejó uno de los pocos ejemplos de arte funerario en la Región de Murcia, aparte de ser una de las obras más sobresalientes del italiano por la delicada ornamentación de los hábitos episcopales y la sutileza con la que fueron grabados los elementos de orfebrería y la ornamentación textil de la ropa.

A simple vista, el Sepulcro del Obispo Almeyda, puede parecer un encargo demasiado presuntuoso. Sin embargo no lo es tanto teniendo en cuenta el gran número de encargos que en aquellas décadas del Siglo XVI se hacían a los talleres de Génova que trabajaban el mármol de Carrara. Según Estella Marcos (1996) el envío de esculturas genovesas a España fue constante, y se mantuvo, aunque con menor intensidad, a lo largo del Siglo XVII. Para Arciniega García (1991) los documentos certifican el movimiento ingente de obras de arte desde Italia coincidiendo con la extensión del gusto a la antigua que se había forjado en el país transalpino.

En Génova los talleres escultóricos trabajaban los mármoles de Massa y de Carrara, que según 'Il Filarete' eran los más gentiles y nobles dentro de todos los

\footnotetext{
${ }^{4}$ Juan de Orea fue el tasador oficial del Sepulcro del Obispo Almeyda, y su único peritaje fue más que suficiente para que Bartolomé de Lugano aceptase el costo de dicha obra.
} 
mármoles. Por tanto, no es de extrañar, que el Obispo Esteban de Almeyda, recurriera a un encargo genovés para diseñar su monumento funerario, lo cual cobra más sentido sabiendo que el propio Obispo Almeyda había hecho gala de un fuerte impulso humanista como el que llegaba desde Italia. Además como comentan López Torrijos y Nicolau Castro (2002) el prestigio de quien preside el sepulcro va unido a la propia obra y al material del que está hecha lo cual hace que cada vez más los encargos se concentren en Génova. La multitud de pedidos y la instalación de los sepulcros en España, hacía que fuese necesario crear Sociedades o Compañías de intermediarios que pusiera en contacto a los clientes españoles y a los escultores genoveses, facilitando así, que muchos clientes españoles accedieran a una escultura renacentista italiana que, de otra forma, hubiera sido imposible. Y aunque fue el arte sepulcral el preferido por los patronos españoles, no hay que olvidar como indican López Torrijos y Nicolau Castro (2002) que también llegó una gran cantidad de escultura de devoción tanto de bulto redondo como en relieve.

En el caso de Sepulcro del Obispo Esteban de Almeyda, que es el que nos ocupa, la obra, como dijimos antes, sigue la estela del sepulcro vaticano del Papa Sixto IV, aunque el sepulcro murciano se diferencia del túmulo papal en la decoración de los laterales cóncavos, que en esta ocasión se decoran con relieves ovalados flanqueados por las figuras de los evangelistas desprovistas de cualquier tipo de marco.

El sepulcro, en palabras de Torres-Fontes (2002) estuvo empotrado durante años en un testero del Evangelio en la capilla mayor de la Iglesia de San Esteban en un arco de mampostería de estilo herreriano, tal como lo describe Gutiérrez-Cortines Corral (1972), distribuyéndose las partes de forma arbitraria: los laterales - que según la descripción de Fuentes y Ponte (2005) miden 2'38 metros de longitud- del sepulcro aparecen superpuestos, las partes trapezoidales aparecen dentro del nicho y coronando el arco junto al sombrero episcopal, mientras que las cuatro esculturas que estaban en las esquinas de la tumba se colocaron dos dentro del nicho y otras dos coronando las esquinas del frontón que remataba el arco. Y pudo perderse el sepulcro, ya que tras la expulsión de los jesuitas, el Colegio y la Iglesia de San Esteban fueron dedicados desde 1769 a Real Hospicio y Casa de la Misericordia, según las gestiones que había iniciado Pedro Rodríguez de Campomanes, aunque antes de recibir a La Casa de la Misericordia hospedó durante un corto periodo de tiempo a la Compañía de Dragones de la Reina. Pese a este nuevo uso, en la Real Cédula dictada por el monarca se dejaba bien claro que se debían guardar y respetar todos aquellos derechos - incluyendo, claro está, las sepulturas - que hubiera adquirido una persona dentro del conjunto. Más tarde el Colegio y la Iglesia de San Esteban pasaron a ser Manicomio Provincial y, durante la Guerra Civil, fue ocupado transitoriamente por las tropas del ejército provocando algunos daños irreparables, hasta que en 1972 se planteó el derribo de todo el conjunto arquitectónico debido a la situación de ruina que sufría, y terminó por ser restaurado para albergar el Museo del traje folclórico y el centro de actividades culturales de la Diputación Provincial. En 1984 la Comunidad Autónoma de la Región de Murcia eligió este antiguo Colegio para ser la sede del Gobierno Regional. Pese a conservarse el Conjunto, la Iglesia pasó a ser una sala de exposiciones temporales, por lo que el Sepulcro del Obispo Almeyda fue retirado del crucero del templo.

En cuanto a la forma, el Sepulcro obedece al tipo sixtino de efigie yacente sobre rico lambrequín y un pedestal con paredes cóncavas. El Obispo luce las ropas litúrgicas propias de su dignidad, destacando la rica dalmática recamada y la casulla romana ejecutada con gran maestría mostrando un brocatel con cenefa bordada en el centro con imágenes religiosas como son las de San Pedro in pectore, San Juan Evangelista y una mártir labrada de forma sobresaliente. El Obispo lleva también las manos enguantadas con sortijas y una espectacular mitra con cabujones y piedras 
preciosas engastadas. Descansa la cabeza sobre ricos almohadones, y junto a ella, el báculo vegetalizado muestra la dignidad del Obispo.

El rostro del Obispo es noble, reproduciendo su mentalidad eclesiástica y autoritaria, sin embargo la dulzura del gesto le acerca más al sueño que a la muerte, quedando así patente un acusado carácter humanista en el retrato.

El pódium del sepulcro queda decorado en los lados mayores por dos relieves orlados flanqueados por las imágenes de los evangelistas. La diferencia entre la escultura yacente y la de los relieves es notable, siendo en las escenas del pedestal donde se observa un mayor carácter italiano deudor del renacimiento que se desarrolla en los talleres lombardos. Para Gutiérrez-Cortines (1972), el relieve con la escena de la lapidación de San Esteban tiene como claro referente al cuadro pintado por Giulio Romano en la Iglesia de Santo Stéfano de Génova. En el relieve murciano queda al descubierto un excelente trabajo en el estudio de la perspectiva y los contrastes entre luz y sombra. En el relieve opuesto, el de la Coronación y Asunción de la Virgen, la escena se presenta con unos ángeles asistentes que quedan armoniosamente distribuidos en la obra con las nubes de fondo. En ambos casos, el relieve gradual es concebido como base para la creación de la perspectiva y la profundidad, aunque las figuras en escorzo contribuyen también a potenciar la sensación de profundidad y las tensiones dramáticas, en un juego de contrastes en el que la luz es uno de los principales protagonistas de un claroscuro que confiere de un gran volumen a las figuras.

Los evangelistas, a su vez, recogen ciertas influencias del manierismo con unos rasgos muy vitales y una grandilocuencia exagerada desarrollada gracias a los movimientos ampulosos que trascienden la propia exigencia de la imagen. San Marcos y San Mateo muestran unos tejidos caprichosos que envuelven las cabezas describiendo un semicírculo que equilibra la posición diagonal de la pierna izquierda a la vez que se contrapone con el gesto del brazo derecho. Todo esto, así como la manera de distribuir en círculos concéntricos las telas de los hombros, puede relacionarse, según Gutiérrez-Cortines, con los ángeles tenantes del sepulcro de Don Pedro Enríquez, hecho por Antonio Aprile en la Universidad de Sevilla, y con el de doña Catalina Ribera realizado por Pace Gazini que se encuentra en la misma capilla. Lo cual habla claro de las relaciones personales entre los artistas lombardos que trabajan en España durante el Siglo XVI.

Completan el sepulcro el relieve frontal con el escudo de armas de los Almeyda, y cuatro figuras de bulto colocadas en las esquinas del túmulo. El escudo familiar aparece sin sombrero episcopal según lo describe Torres-Fontes: Enmarcado en cartela de cueros recortados y está compuesto por seis roeles y un león rampante en dos campos partidos en palo. (2002)

En cuanto a las cuatro figuras de bulto redondo de las esquinas son de una enorme rigidez y presentan una composición cerrada, como un bloque, sin una búsqueda de efectos expresivos o movimientos.

\section{El retrato infantil funerario en el siglo XIX}

Como ya comentamos anteriormente en la introducción, el retrato de difunto comienza a convertirse desde el siglo XVII en una costumbre dentro del seno de las familias como una manera de dejar constancia de la muerte de un ser querido y recordarle así para la eternidad. Esta clase de representaciones tienen su origen en las imágenes maiorum que la cultura romana extiende por todos los rincones de Europa y que eran mascarillas funerarias hechas en yeso a partir del rostro del difunto, de forma que su físico permaneciese junto a la familia como señal de dignidad y honra para todo el conjunto familiar. 
Para Borrás Llop (2010) este tipo de representaciones nos puede ayudar mucho a la hora de trazar un estudio socio-cultural de la familia. Él se adhiere a las ideas de Goody (2001) que habla de que los ritos funerarios ayudan a comprender mejor las relaciones dentro del núcleo familiar, y desmiente así a otros historiadores que citaban el nacimiento de la familia afectiva en las familias europeas exclusivamente.

En el caso español el retrato de difunto quedó reservado durante los siglos XVII y XVIII a las clases más altas de la sociedad, y su expansión entre el resto del pueblo se produjo en el momento en el que el género del retrato atravesó las paredes del hogar y alcanzó un sentido íntimo y privado durante el siglo XIX. En este siglo el retrato de difunto ya no era sólo competencia de la pintura si no que debía competir con la fotografía, que al final, acabó por imponerse.

Como indica Gutiérrez García (2005: 285) el retrato de difunto fue una constante durante todo el siglo XIX, y en algunos casos se unió esta costumbre con el retrato infantil que también gozó de gran éxito en esta centuria. Sin lugar a dudas, durante este siglo se potenció sobre manera la cultura del sentimiento, en el que el retrato mostró la unión familiar a través de ideas como el cariño o la ternura en lugar de la tópica jerarquía que habíamos visto en el pasado. En este sentido el retrato infantil funerario cobró un doble sentido, por un lado dejar constancia de la muerte del pequeño, y por otro mostrar el cariño de la familia por uno de sus miembros.

\subsection{Niña muerta}

Este doble significado lo cumple el único retrato de este tipo que se encuentra en la colección de arte autonómica, y que se titula Niña muerta. La obra debida al pincel del caravaqueño Rafael Tegeo, se debió realizar durante la primera mitad del siglo XIX y es un óleo sobre lienzo que mide 74 por $96 \mathrm{~cm}$.

Aunque la biografía de Rafael Tegeo es bien conocida, sorprende la versatilidad de su técnica, que bien se atreve con la pintura de historia, la mitológica o el retrato cumpliendo siempre con obras de lo más correctas en cuanto a la técnica. Y, aunque conviene decir que fue el retrato el género en el que se movió el pintor, la representación que ahora tratamos suponía un reto para el pintor, tanto desde el punto de vista temático como técnico, puesto que, según Gutiérrez García (2005) este tipo de cuadros suponen un singular sentido morboso en el que los parámetros academicistas se entreverán con postulados románticos.

En el retrato de Tegeo (Fig. 2) se observa la figura de la niña difunta recientemente, recostada, de cuerpo entero y en soledad, lo que era una constante en la gran mayoría de obras de esta tipología -bien fuera en pintura o fotografía- según comenta Borrás Llop (2010).

En el caso de nuestro retrato la niña reposa sobre un gran almohadón azul que hace las veces de colchón, y éste se encuentra sobre una mesa forrada con una tela de terciopelo rojo. La niña viste una indumentaria bautismal, pintada con todo detalle y primor. Una prenda delicada en la que destaca su decoración floral y los suaves colores.

Su cabeza, cubierta en parte por un gorro de estilo vegetal, muestra una cara tranquila y serena, que sugiere, más que la muerte, una expresión durmiente en la pequeña. El hecho de que se cubra la cabeza con un elemento de carácter floral viene motivado por la tradición cristiana del ritual funerario infantil. El Ritual romano, que compiló Paulo V en 1614 hablaba de la ceremonia dedicada a los párvulos, y explicaba que debía aparecer sobre sus cabezas una corona de flores para representar la entereza de su carne y virginidad (Righetti, 1964). Se completa la composición con un cortinaje azul oscuro con motivos florales en blanco, y un fondo exterior que complementa la imagen de la niña y que representa un crepúsculo en el que el sol se esconde tras las montañas. 


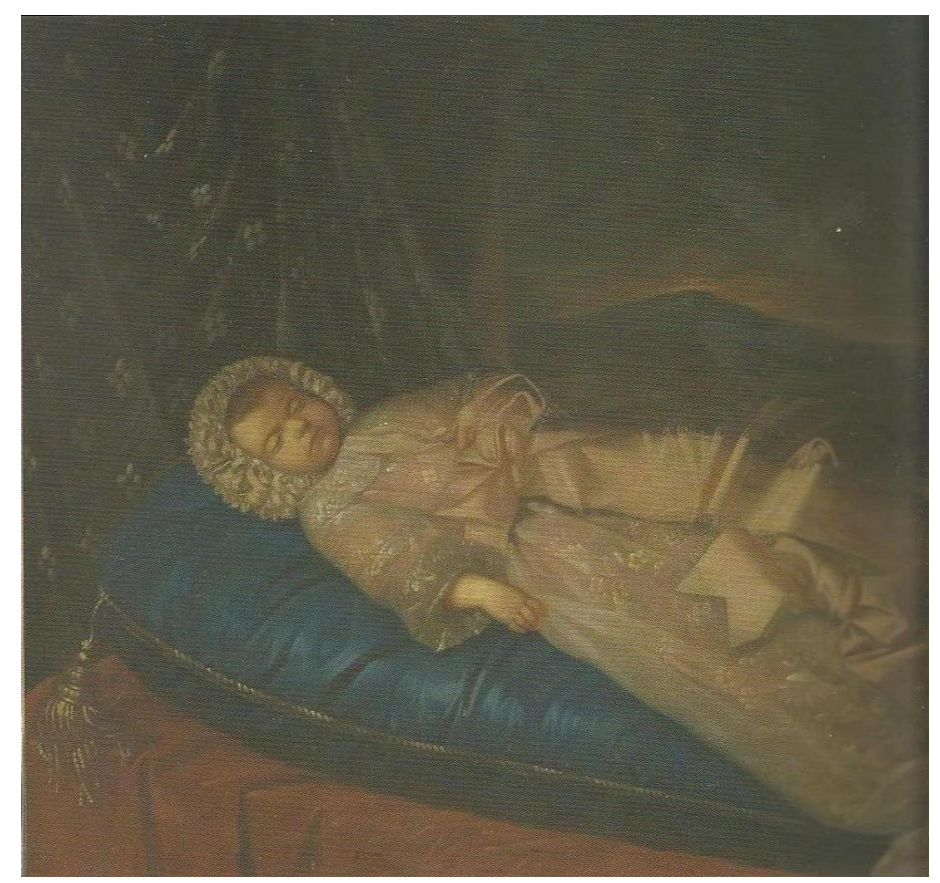

Figura 2. Rafael Tegeo. Niña muerta. h. 1830. CARM.

\section{Conclusiones}

La tipología que ha sido considerada por un elevado número de autores como el origen mismo del género del retrato, es el retrato funerario, que ha ocupado la investigación y análisis de este artículo.

Para muchos el retrato nace de la intención de las civilizaciones antiguas de conservar la efigie de los muertos para poder mantener vivo así su recuerdo. Y quizás ese afán de "recuerdo eterno" se halle detrás, en cierta manera, de todas las representaciones del género del retrato.

Dentro de nuestro trabajo, sólo hemos analizado dos obras que respondan a esta tipología. La primera de ellas es un sepulcro renacentista -la obra más antigua de toda la colección autonómica- que refleja plenamente la concepción que el Renacimiento tenía sobre la muerte, ya que el protagonista yace sereno y noble en su tumba, como signo inequívoco del triunfo de la fama del hombre sobre la propia muerte.

La otra obra de carácter funerario, que hoy en día puede producir un cierto choque cultural, era una representación bastante habitual en España desde el siglo XVII y que se mantuvo, gracias a la fotografía hasta bien entrado el siglo XX. Se trata, en este caso, del retrato de difuntos representando a una niña pequeña.

En definitiva dos obras de carácter excepcional que no son habituales en colecciones públicas de arte y que son buena muestra de las diferentes concepciones que ha tenido el retrato funerario a lo largo de los siglos.

\section{Referencias}

Alcázar, B. (1710). Cronohistoria de la Compañía de Jesús. Década II (Capítulo I-I)

Arciniega García, L. (2006). El mediterráneo como soporte para intercambios culturales en El comercio y el Mediterráneo. Valencia y la cultura del mar. Valencia: Generalitat Valenciana 
Borrás Llop, J.M. (2010). Fotografía/Monumento. Historia de la infancia y retratos postmortem. Madrid: Hispania, revista española de historia.

Cadiñanos, I. (1983). Felipe Bigarny, Alonso Berruguete y los sepulcros de los Condestables en Burgos. Madrid: Archivo Español de Arte

Estella Marcos, M. (1996). Un sepulcro genovés y otro encargado a Liceire para los Moncada. Madrid: Boletín del seminario de Estudios de arte y arqueología, tomo 62. 395-400

Fuentes y Ponte, J. (2005). España Mariana: Provincia de Murcia. Murcia: Fundación Centro de Estudios Históricos e investigaciones locales de la Región de Murcia.

González de Zárate, J.M. (1989). El arte sepulcral como una de las mayores manifestaciones del renacimiento en la Vitoria del siglo XVI. San Sebastián: Eusko Ikaskuntza

Goody, J. (2001). La familia europea. Barcelona: Crítica

Gutiérrez-Cortines Corral, C. (1972). La Iglesia y el Colegio de San Esteban. Murcia: Patronato de Cultura de la Excma. Diputación Provincial.

Gutiérrez García, M.A. (2005). El Museo de Bellas Artes de Murcia. La colección permanente. Murcia: Consejería de Cultura. CARM.

López García, M.A. (2006). Aproximación a la gestión municipal del Real Hospicio y Casa de la Misericordia de Murcia en el último tercio del siglo XVIII: Las temporalidades de los jesuitas en La iglesia española y las instituciones de caridad. San Lorenzo del Escorial: Ediciones Escurialenses.

López Jiménez, C. (1970). Murcia: 22 de Noviembre de 1970 en el Diario Línea López Torrijos, R. y Nicolau Castro, J. (2002). La familia Cárdenas, Juan de Lugano y los encargos de escultura genovesa en el siglo XVI. Madrid: Boletín del seminario de estudios de arte y arqueología, tomo 68. 169-190

López Torrijos, R. (1987). La scultura genovesa in Spagna en La scultura a Genova e in Liguria: dalle origini al cinquencento. Genova: Fondazione Cassa di risparmio

Marqués de Lozoya (Juan de Contreras y López de Ayala). (1957). Escultura de Carrara en España, Madrid: Instituto Diego Velázquez

Panofsky, E. (1964). Tomb sculpture. London: Thames\&Hudson

Redondo Cantera, M. J. (1986). El Sepulcro de Sixto IV y su influencia en la escultura del Renacimiento en España. Madrid: Boletín del seminario de arte y arqueología. 271-282

Righetti, M. (1964). Manuale di storia litúrgica. Milán: Àncora

Torres-Fontes Suárez, C. (2002). Sepulcro de Don Esteban de Almeyda en Huellas. Murcia: Fundación Cajamurcia. 